\title{
RANCANG BANGUN SISTEM INFORMASI SATGAS GOTONG ROYONG (SI GARONG) DESA ADAT BERBASIS MOBILE
}

\author{
Ketut Agus Seputra ${ }^{1}$, Gede Sandiasa ${ }^{2}$ \\ ${ }^{1}$ Manajemen Informatika, Universitas Pendidikan Ganesha \\ Singaraja, Indonesia \\ ${ }^{2}$ IImu Administrasi Negara, Universitas Panji Sakti \\ Singaraja, Indonesia
}

e-mail: agus.seputra@undiksha.ac.id ${ }^{1}$, gede.sandiasa@unipas.ac.id ${ }^{2}$

\begin{abstract}
Abstrak
Pandemi Covid 19 telah dinyatakan Pemerintah Indonesia sebagai Bencana Nasional, oleh karena itu diperlukan partisipasi semua pihak dalam upaya melaksanakan pencegahan dan penanganan bencana ini. Bali sebagai salah satu tujuan wisata mancanegara wajib memastikan masyarakatnya untuk taat pada protokol penanganan dan pencegahan Covid 19. Dalam kesatuan masyarakat dan mencakup wilayah yang terkecil, maka desa sebagai ujung tombak pelayanan pemerintah harus mengambil peran yang penting dalam kegiatan ini. Melalui lembaga Desa Adat, Pemerintah Provinsi Bali menggunakan kearifan lokal dalam meningkatkan partisipasi masyarakat Bali dan lembaganya untuk terlibat aktif dalam kegiatan pencegahan dan penanggulangan, serta mengatasi dampak Covid 19. Demikian pula Desa Adat Sangket sebagai sebuah organisasi adat dan keagamaan ikut mengambil peran penting dalam penanganan kegiatan pencegahan Covid 19 melalui pembentukan Satuan Tugas (SATGAS) Gotong Royong Pencegahan Covid 19 Desa Adat. Melalui pengembangan Sistem Informasi Satgas Gotong Royong (SI Garong) Covid 19 berbasis mobile diharapkan dapat membantu kinerja satgas, serta meningkatkan partisipasi masyarakat dalam upaya penanganan dan pencegahan Covid 19. Sistem Informasi dikembangkan cross-platform menggunakan framework flutter. Seluruh fitur dalam aplikasi telah diuji dan dinyatakan sesuai dengan kebutuhan pengguna.
\end{abstract}

Kata kunci: Covid 19, flutter, web service, aplikasi mobile

\begin{abstract}
Covid 19 has approved the Government of Indonesia as a National Disaster. All parties are required to participate in efforts to repair and handle this disaster. Bali as one of the international tourist destinations is obliged to ensure its people to abide by the Covid protocol of regulation and coverage. In the context of the community including the region, the village as the spearhead of the government must take an important role in this activity. Through the Desa Adat, the Provincial Government of Bali uses local wisdom in increasing the participation of Balinese people and their institutions to be actively involved in prevention and mitigation activities, and to overcome the Covid 19. conflict. Similarly, the Desa Adat Sangket as a traditional and religious organization takes an important role in handling Covid 19 prevention activities through the establishment Satuan Tugas (SATGAS) Gotong Royong. Through the development of a mobile-based Satgas Gotong Royong Covid 19 Information System, it is hoped that it can help the task Satgas performance, as well as increase public participation in the handling and prevention of Covid 19. The information system is developed cross-platform using a flutter framework. All features in the application have been tested and stated according to user requirements..
\end{abstract}

Keywords : Covid 19, flutter, web service, mobile apps 
ISSN 2089-8673 (Print) | ISSN 2548-4265 (Online)

Volume 9, Nomor 3, Desember 2020 


\section{PENDAHULUAN}

Kedudukan desa adat sebagai lembaga otonom, sudah mendapat pengakuan dalam Undang-undang, sehingga kearifan lokal masyarakat adat dapat menjadi acuan dalam pembangunan[1]. Realitas ini diakui dan difungsikan oleh pemerintah Provinsi Bali, dalam rangka penanganan penyebaran wabah covid 19, sebagai upaya penggunaan kearifan lokal dalam meningkatkan partisipasi masyarakat Bali dan lembaganya untuk terlibat aktif dalam kegiatan pencegahan dan penanggulangan, serta mengatasi dampak Covid 19. Wabah Covid 19, telah dinyatakan pemerintah sebagai bencana nasional, diperlukan partisipasi semua pihak dalam upaya melaksanakan pencegahan dan penanganan bencana ini. Dalam kesatuan masyarakat dan mencakup wilayah yang terkecil, maka desa sebagai ujung tombak pelayanan pemerintah, harus mengambil peran yang penting dalam kegiatan ini. Namun demikian beberapa wilayah di Bali masuk dalam penyelenggaraan pemerintahan menjadi desa administratif atau kelurahan yang tidak memiliki cukup anggaran, sebagaimana desa dinas yang memiliki ADD (Alokasi Dana Desa). Untuk memperkuat keberadaan satgas penanggulangan covid 19, maka pemerintah provinsi Bali melibatkan Desa Adat, untuk membantu penanganan bencana ini, sebab pengaturan yang paling sulit dilakukan adalah berkaitan dengan masyarakat dalam menyelenggarakan kegiatan keagamaan dan adat istiadat [2]. Dengan demikian berbagai pengaturan termasuk pembentukan satgas pencegahan Covid 19 yang melibatkan desa adat dan desa dinas. Demikian pula Desa Adat Sangket sebagai sebuah organisasi adat dan keagamaan ikut mengambil peran penting dalam penanganan kegiatan pencegahan Covid 19 melalui pembentukan Satuan Tugas (SATGAS) Gotong Royong Pencegahan Covid 19 Desa Adat.

Meskipun telah digulirkan beberapa regulasi namun tidak banyak dapat membantu desa adat dalam operasionalnya, sebab desa adat tidak memiliki anggaran yang cukup, sumberdaya yang tidak memadai dan tidak memiliki relawan terlatih dalam penanganan wabah virus corona. Mengingat kegiatan bencana wabah Covid 19 oleh desa adat dapat dipilah menjadi tiga [3], yaitu:

a. Pencegahan melalui kegiatan sosialisasi, edukasi, dan penyemprotan disinfektan.

b. Penanganan terdiri dari kegiatan koordinasi pihak-pihak, karantina dan penanganan kesehatan, pengawasan dan monitoring, penerimaan dan distribusi bantuan, dapur umum, pengendalian keluar masuk penduduk, laporan dan publikasi.

c. Penanganan dampak pasca bencana meliputi penanganan trauma bencana, ketertiban dan keamanan desa, penanganan ekonomi masyarakat, penguatan kerjasama dan solidaritas sosial, serta tertib kependudukan.

Dengan keterbatasan tersebut, serta dampak yang ditimbulkan sangat parah baik menyangkut kesehatan maupun pertumbuhan ekonomi masyarakat, yang dapat pula menimbulkan gangguan keamanan dan ketertiban umum, maka dibutuhkan sarana bantu untuk memudahkan pekerjaan desa adat khususnya satgas gotong royong, sebagai ujung tombak dalam penanganan Covid 19. Penerapan aplikasi berbasis Teknologi Informasi untuk dapat mengatur upaya pencegahan dan penanganan covid 19 serta pemantauan dampak pasca covid 19 dapat menjadi salah satu solusi yang dapat ditempuh. Didukung oleh semakin meningkatnya pengguna smartphone dalam satu tahun terakhir mencapai 2.87 miliar pengguna [4], maka pengembangan aplikasi mobile manjadi pilihan yang tepat. Namun perlu dipertimbangkan agar aplikasi yang dikembangkan mampu berjalan pada beberapa platform yang berbeda, mengingat market share pada tahun 2018 terdapat $77 \%$ pengguna android, $21 \%$ pengguna ios, dan $2 \%$ dari platform lainnya[4]. Untuk itu, pengembangan aplikasi mobile dilakukan dengan pendekatan cross-platform menggunakan framework flutter. 
ISSN 2089-8673 (Print) | ISSN 2548-4265 (Online)

Volume 9, Nomor 3, Desember 2020 


\section{KAJIAN TEORI}

Aplikasi Mobile

Aplikasi mobile merupakan sebuah perangkat lunak yang dirancang untuk dapat berjalan pada perangkat bergerak salah satunya smartphone. Smartphone sebagai high end mobile phone yang dilengkapi dengan kemampuan mobile computing. Dengan kemampuan tersebut, pengguna dapat dengan mudah menambahkan aplikasi dan menambahkan fungsi-fungsi sesuai kebutuhan pengguna dengan performa yang cukup tinggi. Kemudahan dalam pengoperasian juga menjadi salah satu faktor yang menyebabkan semakin meningkatnya pengguna smartphone dalam satu tahun terakhir.

\section{Rest API}

Penggunaan smartphone sangat meningkat dalam satu dekade terakhir. Sebagian besar aplikasi mobile dikembangkan untuk sistem terintegrasi antar platform menggunakan arsitektur remote services untuk alasan efisiensi dan keamanan data. REST (Representational State Transfer) API (Application Programming Interfaces) telah menjadi bentuk layanan utama selama beberapa tahun terakhir untuk melakukan tujuan tersebut khususnya pada aplikasi mobile. REST mentransformasikan satu atau beberapa bisnis logic atau class dan objek yang terpisah dalam satu ruang lingkup yang menjadi satu sehingga tingkat keamanan dapat ditangani dengan baik. REST juga mudah dalam hal pengembangan, karena tidak memerlukan registrasi khusus ke dalam suatu sistem operasi. Cukup dengan upload dalam web server, kemudian memberikan hak akses kepada pihak-pihak yang diberikan otorisasi. Beberapa hal tersebut yang membuat REST API ringan, mudah diimplementasikan, dan sangat fleksibel untuk pengembangan perangkat mobile [5]. REST sebagai pihak ketiga berfungsi menyediakan layanan API untuk pertukaran data antara flutter dengan website sebagai pengelola data.

\section{Json (JavaScript Object Notation)}

JSON digunakan sebagai format pertukaran data yang pada API. Dibandingkan dengan format XML, JSON lebih ringan, mudah dibaca dan ditulis oleh manusia, serta mudah diterjemahkan dan dibuat (generate) oleh komputer, sehingga sangat mudah diimplementasikan untuk pertukaran data dalam aplikasi mobile [5][6]. JSON sangat baik digunakan dalam mekanisme perukaran data dalam topologi client-server[7]. Terdapat beberapa bentuk yang dapat digunakan dalam mekanisme pertukaran data dalam json antara lain, object, array, value, dan string. Object lebih menekan kan pertukaran terhadap data tunggal, sementara array digunakan untuk data dalam bentuk jamak berupa list atau urutan data[6]. Dalam satu pertukaran data harus terdapat sebuah object yang dapat mendefinisikan keadaan data secara ringkas. Objet tersebut yaitu data, errors, dan meta objet data ini disebut top level[8]. Data digunakan untuk merepresentasikan dokumen utama berisi data pokok, errros untuk memberikan informasi kepada pengguna mengenai deskripsi error, serta meta object berisi beberapa informasi tambahan terkait response data. Berikut contoh format JSON yang digunakan.

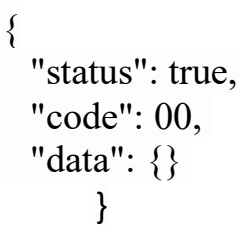

\section{JWT (JSON Web Token)}

Layanan API dirancang agar dapat melakukan pertukaran data secara aman menggunakan konsep JWT (JSON Web Token). JWT merupakan mekanisme autentikasi pada pertukaran informasi REST API menggunakan sebuah token berbentuk string yang terdiri dari header, payload, dan signature [9]. Token diperoleh setelah pengguna berhasil melakukan login menggunakan username, dan password yang disisipkan pada header HTTP request setiap kali melakukan pertukaran data pada API. Adapun token dihasilkan menggunakan encode HMAC yang dapat menghasilkan token secara lebih cepat 
serta tidak tersimpan pada sisi server[10]. Hal ini tentu meringankan proses tokenisasi pada JWT.

\section{Flutter Framework}

Saat ini pengembangan aplikasi mobile berbasis cross-platform menjadi salah satu pilihan untuk mengembangkan aplikasi mobile dengan biaya lebih murah, waktu pengerjaan lebih cepat, tentunya dengan kinerja yang cukup tinggi. Crossplatform yang biasa disebut sebagai WORA (Write, One, Run, Anywhere) memungkinkan sebuah code dapat berjalan pada Android maupun ios. Menggunakan bahasa pemrograman yang terkenal dengan banyak komunitas dapat memudahkan dan mempercepat waktu pengerjaan aplikasi. Terdapat beberapa klasifikasi terkait crossplatform apps, antara lain Web Apps, Hybrid Apps, Interpreted Apps, Widget Based Apps [4].

Flutter merupakan UI (User Interface) framework dan SDK (software development kit) open source berbasis Widget Based Apps, dimana semua komponen dalam aplikasi ini adalah widget yang berfungsi sebagai blok pembangun untuk membentuk antarmuka pengguna aplikasi. Flutter dikembangkan oleh google dapat berjalan pada multiple platform dengan kinerja dan standar keamanan tinggi, serta kemudahan dalam pemeliharaan. Fultter juga dikenal sangat efisien dalam manajemen sumber daya[11]. Sama seperti aplikasi native, flutter juga memiliki akses lengkap ke berbagai perangkat keras yang yang mendasarinya. Dengan menggunakan bahasa dart yang mudah untuk diimplementasikan, serta didukung oleh beragam UI milik google yang dapat berjalan lancar pada berbagai platform menjadikan flutter semakin diminati[12], hingga menjadi framework pengembangan aplikasi mobile yang paling banyak digunakan saat ini [4].

Secara sederhana dapat digambarkan pada gambar 1 , bagaimana sebuah aplikasi mobile melakukan pertukaran data menggunakan layanan API yang dikembangkan menggunakan REST API pada framework Codeigniter, dan flutter sebagai framework pengembangan perangkat mobile.

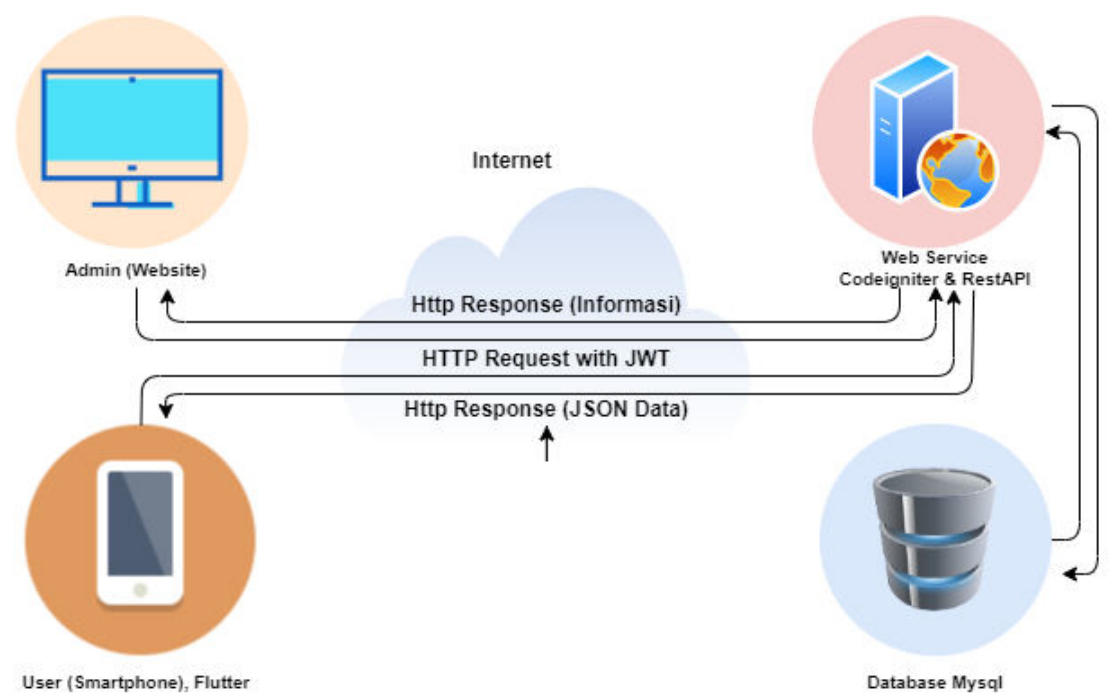

Gambar 1. Arsitektur Sistem

METODE

Penelitian dilakukan menggunakan pendekatan $\mathrm{RnD}$ (Research and Development) sebagai upaya dalam menemukan jawaban atas permasalahan praktis melalui pengembangan sebuah prototipe produk [13]. Penelitian ini fokus pada pengembangan sebuah purwarupa aplikasi mobile untuk Satgas Covid 19 Desa Adat, sehingga metode yang digunakan 
adalah metode pengembangan sistem yaitu ADDIE (Analyze, Design, Development, Implementation, Evaluation). Model ADDIE sangat cocok untuk penelitian pengembangan yang fokus pada urutan intruksional analisis dan perancangan sistem[14]. Adapun tahapan yang dilalui sebagai berikut.

a. Tahap Analyze (analisis) dilakukan pendefinisian permasalahan, tujuan dari pembuatan sistem, serta sasaran. Pada tahap ini secara detail dilakukan analisis terhadap kebutuhan pengguna terkait pengembangan sistem. Beberapa cara dapat dilakukan peneliti mulai dari observasi lapangan, wawancara, maupun studi literatur.

b. Tahap Design (perancangan) merupakan tahapan perancangan sistem berdasarkan kebutuhan pengguna. Luaran dari tahapan ini adalah sebuah rancangan sistem yang jelas dan dan terstruktur menggambarkan alur kerja sistem secara menyeluruh. Tahapan ini menjadi sangat penting dan menentukan bagaimana sistem nanti dikembangkan. Beberapa model yang bisa menjadi acuan dalam pengembangan sistem seperti use case diagram, activity diagram, entity relationalship diagram, dan perancangan antarmuka wajib diselesaikan dengan matang.

c. Rancangan yang telah matang diserahkan kepada programmer untuk selanjutnya menjadi acuan dalam tahap Development (pengembangan). Tahap ini, semua rancangan tersebut diimplementasikan dalam bahasa pemrograman, database, atau perangkat lunak lainnya, serta perangkat keras yang berhubungan dengan pengembangan sistem.

d. Aplikasi yang telah dikembangkan selanjutnya melalui tahap implement (implemenentasi), yaitu mengimplementasikan aplikasi ke web server maupun perangkat keras lainnya. Aplikasi wajib tersebut melalui tahap pengujian yang dapat dilakukan melalui black box testing dan white box testing[15]. e. Tahap evaluate (evaluasi) merupakan tahap menyimpulkan terkait pengembangan dan pengujian sistem. Jika ditemukan ketidaksesuaian detail pengembangan sistem terhadap kebutuhan pengguna, atau terjadi ketidaksempurnaan kinerja aplikasi, maka diperlukan suatu tindakan revisi pada setiap tahap yang dinyatakan bermasalah.

\section{HASIL DAN PEMBAHASAN \\ Analisis}

Tahap analisis diawali oleh observasi dan wawancara langsung menggunakan teknik in-depth interview kepada Sekretaris Tim Satgas Gotong Royong Desa Adat Sangket guna mengidentifikasi permasalahan, tujuan pembuatan aplikasi, sasaran, sumber daya, serta pengguna aplikasi. Adapun hasil observasi dan wawancara menyatakan penerapan aplikasi mobile diharapkan dapat mengatur upaya pencegahan dan penanganan covid 19 serta pemantauan dampak pasca covid 19, yang terdiri dari beberapa poin utama sebagai berikut.

a. Pemantauan pergerakan masyarakat meliputi pencatatan tamu, keluar masuk penduduk, warga datang dari rantau dan PMI, ODP dan PDP. Hal ini dilakukan dalam upaya pencatatan secara detail keberadaan masyarakat. Data yang diperoleh dapat mempermudah satgas dalam hal pemantauan dan pencegahan.

b. Pendataan pemberi dan penerima bantuan (BST) berbasis IT. Pendataan pemberi dan penerima bantuan dilakukan untuk memperoleh data valid terkait sumber bantuan dan penerima bantuan, sehingga pembagian BST tepat sasaran. Pendataan berdasarkan Nomor Induk Kependudukan (NIK) dan Nomor Kartu Keluarga (No KK) dapat menghindari pendataan ganda terhadap penerima BST dalam satu periode.

c. Pendataan dan perencanaan upayaupaya pemulihan setelah terjadinya wabah covid 19, baik melalui usaha pemberdayaan ekonomi, dan sosial. Data yang telah diperoleh oleh Satgas, baik itu terkait pemberi bantuan, 
penerima, maupun masyarakat yang terdampak langsung dapat diolah menjadi bahan pengambilan keputusan terkait pemulihan keadaan pasca pandemi.

d. Menyampaikan komunikasi, edukasi dan sosialisasi tentang berbagai hal yang dilakukan oleh Desa Adat dalam memberikan perlindungan terhadap warga desa dari penyebarluasan wabah Covid 19.

e. Media untuk menyampaikan kritik, dan masukan bagi Desa Adat. Kritik dan masukan menjadi penting untuk meningkatkan jangkauan pemantauan Satgas. Laporan masyarakat menjadi salah satu bentuk partisipasi masyarakat dalam upaya pemantauan dan pencegahan, sehingga semua bentuk laporan wajib untuk ditanggapi oleh Satgas.

f. Penyampaian laporan kegiatan masyarakat yang melibatkan banyak orang, seperti upacara keagamaan, gotong royong, dan rapat-rapat lainnya. Hal ini penting untuk dilakukan agar Satgas mengetahui secara cepat mengenai kegiatan yang akan dan sedang berlangsung di wilayah koordinasinya, sehingga dapat memastikan dan memantau bahwa kegiatan telah mengikuti protokol pencegahan Covid 19.

g. Membangun jaringan kerjasama dan solidaritas sosial dengan pihak-pihak. Data yang telah diperoleh terkait semua fungsi dalam aplikasi dapat menjadi sebuah laporan yang dapat digunakan untuk keperluan administrasi kepada pihak yang berwenang.

Tahap ini dilakukan secara mendetail, sehingga data yang diperoleh sangat lengkap dan terstruktur. Semua data yang telah terkumpul, kemudian dilakukan analisis guna menterjemahkan kebutuhan pengguna kedalam kebutuhan sistem. Adapun beberapa analisis yang dilakukan sebagai berikut.

a. Analisis Kebutuhan Fungsional menitikberatkan pada analisis proses bisnis yang nantinya harus disediakan oleh sistem yaitu sebagai berikut.
1. Aplikasi yang dikembangkan berupa Sistem Informasi Satgas Gotong Royong (SI GARONG) Covid 19 berbasis Mobile.

2. Terdapat dua level pengguna yaitu pengguna biasa dan admin.

3. Sistem dapat melakukan pencatatan masyarakat pendatang, tamu, PMI, ODP, dan PDP.

4. Sistem dapat mencatat kasus Covid 19 tingkat Desa.

5. Sistem dapat melakukan pendataan pemberi dan penerima bantuan.

6. Sistem dapat memberikan informasi edukasi dan sosialisasi terkait kegiatan yang dilakukan Desa Adat dalam menangani Covid 19.

7. Sistem dapat melakukan pendataan saran dan aduan mayarakat kepada tim satgas terkait penanganan Covid 19.

8. Sistem dapat melakukan pendataan kegiatan masyarakat yang melibatkan banyak orang.

b. Analisis Kebutuhan Non-fungsional dilakukan terkait dengan prilaku yang harus dimiliki oleh sistem[15], yaitu sebagai berikut.

1. Portability, aplikasi harus dapat digunakan pada perangkat mobile dengan sistem operasi android maupun ios.

2. Security merupakan aspek terpenting dalam melindungi data masyarakat. Selain keamanan dari sisi server, aplikasi juga dilengkapi dengan proses login pengguna.

3. Usability berhubungan dengan kemudahan dalam penggunaan aplikasi, sehingga penting aplikasi dirangcang untuk mudah digunakan oleh masyarakat umum.

c. Analisis Kebutuhan Perangkat Lunak berkaitan dengan pengidentifikasian kebutuhan perangkat lunak dalam pengembangan aplikasi antara lain Editor Visual Code, Flutter Framework, Codeigniter, Mysql Database, Xampp, Adobe Photoshop, dan Draw.io.

d. Analisis Kebutuhan Perangkat Keras berkaitan dengan pengidentifikasian kebutuhan perangkat keras dalam pengembangan aplikasi antara lain 
Laptop yang memiliki spesifikasi minimal RAM $8 \mathrm{~GB}$, Hardisk 1TB, dan Processor Intel Core i5.

Kebutuhan fungsional yang telah diidentifikasi penting untuk dimodelkan menggunakan UML (Unified Modelling Language) guna mengidentifikasi akses yang diperoleh masing-masing aktor. Aktor dapat diartikan sebagai segala hal diluar sistem yang akan berinteraksi langsung menggunakan sistem tersebut. Adapun model pengguna dapat digambarkan dalam Use Case Diagram pada gambar 2 .

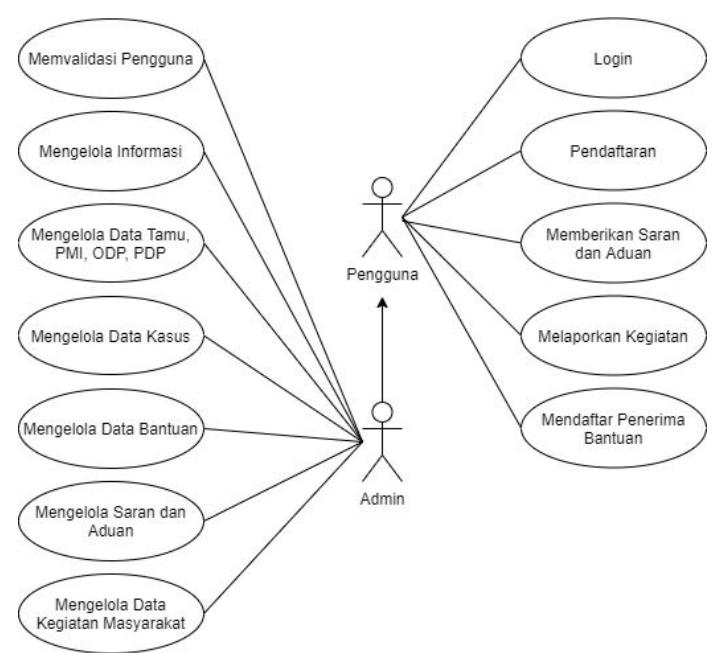

Gambar 2. Use Case Diagram

\section{Perancangan}

Perancangan sistem dilakukan secara mendetail sesuai spesifikasi kebutuhan sistem yang telah dianalisis pada tahap sebelumnya. Beberapa diagram sangat diperlukan guna memperjelas fitur serta alur kerja sistem, sehingga tahapan ini dapat menghasilkan suatu blue print sistem yang detail serta terstruktur.

a. Arsitektur Sistem

Aplikasi dikembangkan menggunakan framework flutter dengan pendekatan web service. Sehingga memungkinkan aplikasi dioperasikan melalui smartphone baik android maupun ios, serta website. Website digunakan oleh administrator untuk manajemen data lebih detail terkait aktivitas yang dilakukan oleh pengguna melalui smartphone. Hal ini dimungkinkan karena pertukaran data terjadi pada satu database melalui $A P I$ seperti pada gambar 1.

b. Rancangan Antarmuka

Perancangan antarmuka merupakan aktivitas penting dalam pengembangan sistem. Tahapan ini harus memperhatikan beberapa aspek terkait pengalaman pengguna dalam menggunakan sistem antara lain antarmuka harus sederhana dan mudah digunakan, lengkap memenuhi kebutuhan pengguna, dan memiliki kinerja yang cepat. Berikut dipaparkan beberapa rancangan antarmuka yang telah dibuat menggunakan perangkat lunak draw.io.

1. Pendaftaran

Gambar 3 merupakan rancangan desain antarmuka pendaftaran pengguna melalui smartphone.

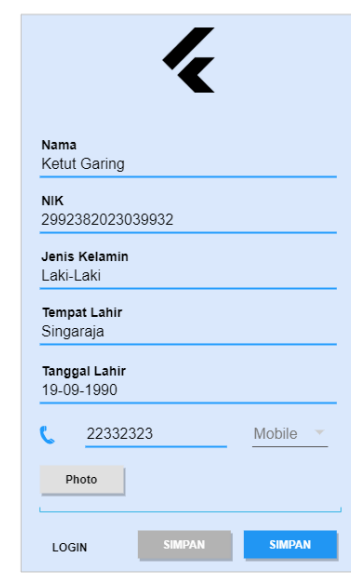

Gambar 3. Pendaftaran Pengguna

2. Beranda

Gambar 4 memperlihatkan rancangan antarmuka dasboard admin pada smartphone.

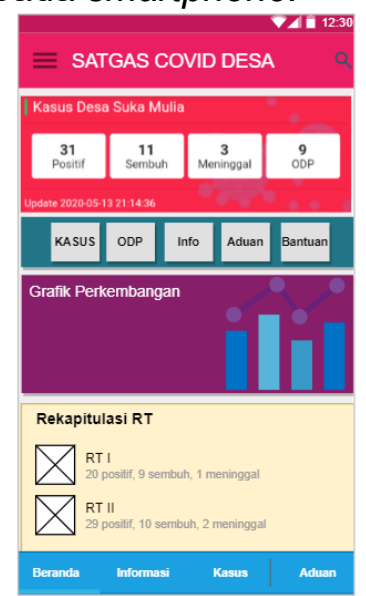


Gambar 4. Beranda

c. Activity Diagram

Activity diagram menggambarkan urutan kerja dari suatu aktivitas dalam sistem. Diagram ini penting untuk mengetahui urutan proses dari suatu aktivitas yang melibatkan banyak aktor. Berikut dipaparkan beberapa Activity diagram yang melibatkan dua level pengguna.

1. Pendaftaran Pengguna

Proses pendaftaran pengguna melibatkan admin sebagai validator pengguna seperti terlihat pada gambar 5. Pengguna melakukan registrasi, selanjutnya divalidasi oleh admin untuk menggunakan sistem secara keseluruhan. Namun apabila ditemukan kesalahan data, maka admin akan menolak pendaftaran pengguna untuk selanjutnya dapat diperbaiki lagi.

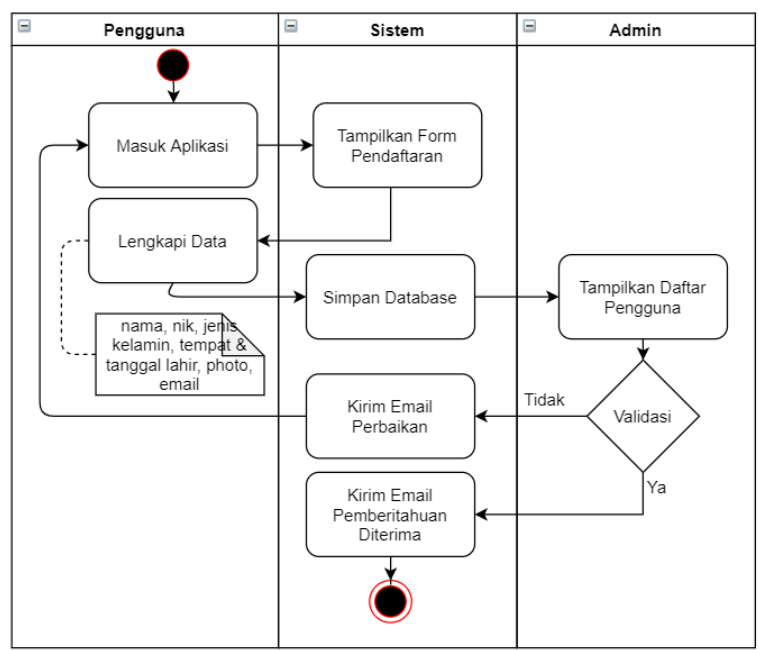

Gambar 5. Diagram Activity Pendaftaran

2. Pengaduan Masyarakat

Proses pengaduan masyarakat melibatkan admin untuk memberikan respon terhadap aduan seperti pada gambar 6. Respon dapat berupa pesan, ataupun perubahan status laporan. Proses aduan akan terus berjalan hingga admin mengubah status aduan menjadi selesai, atau respon admin tidak ditanggapi lagi oleh masyarakat.

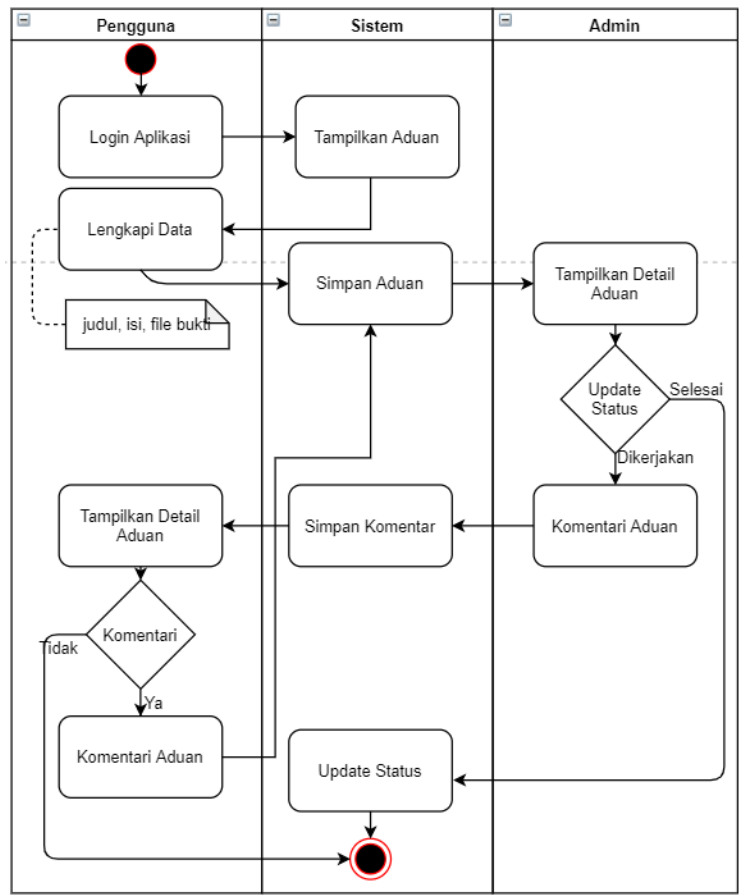

Gambar 6. Activity Diagram Aduan Masyarakat

d. Entity Relationalship Diagram (ERD) ERD merupakan sebuah diagram struktural yang digunakan untuk merancangan sebuah skema database. ERD dapat menjelaskan komponen data atau entity set dan hubunganya melalui relationship set, serta banyak anggota dalam suatu himpunan melalui constraints[16]. Physical Data Model (PDM) merupakan tahapan terakhir dalam perancangan database. PDM memberikan gambaran secara mendetail dari database yang dibuat dengan mempertimbangkan Database Management System (DBMS) yang akan digunakan, dalam hal ini menggunakan DBMS Mysql seperti pada gambar 7 . 


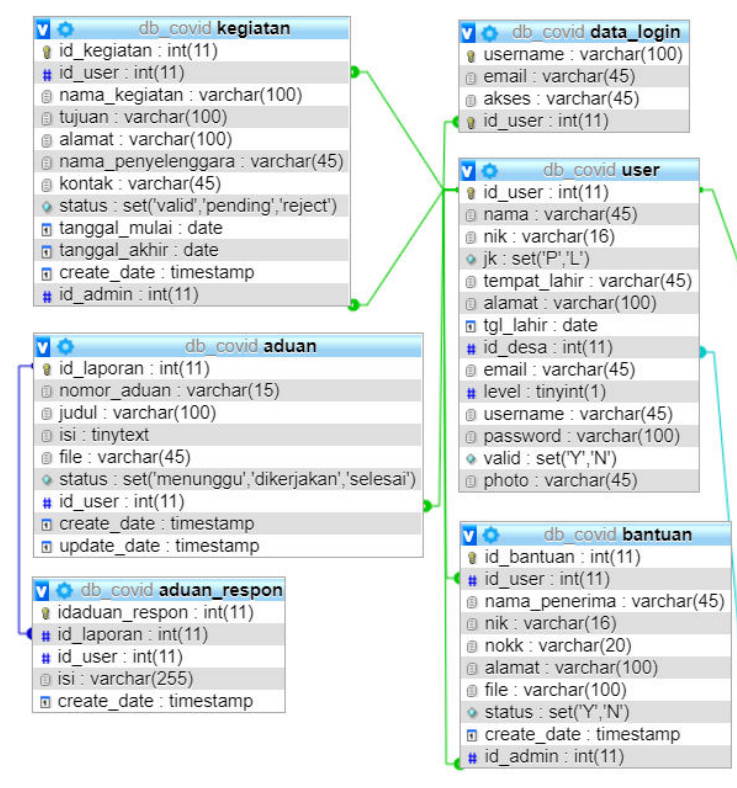

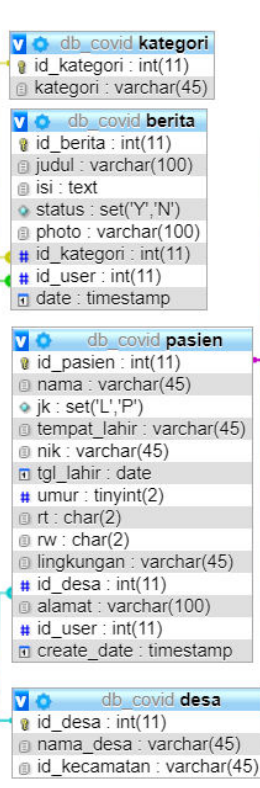

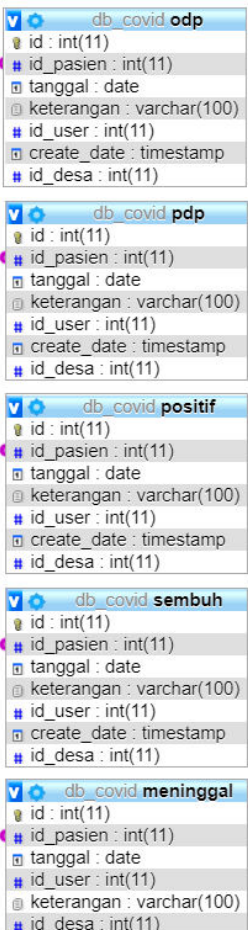

Gambar 7. Physical Data Model

\section{Pengembangan}

Prototipe aplikasi dikembangankan sesuai dengan rancangan sistem yang telah dibuat. Arsitektur sistem berbasis web service diterjemahkan kedalam scope model dalam flutter seperti pada gambar 8. Penggunaan scope model dapat mempermudah dalam hal penulisan code, pemeliharaan hingga pengujian. Sehingga dihasilkan aplikasi yang lebih ringan, efektif, dan efisien [17].

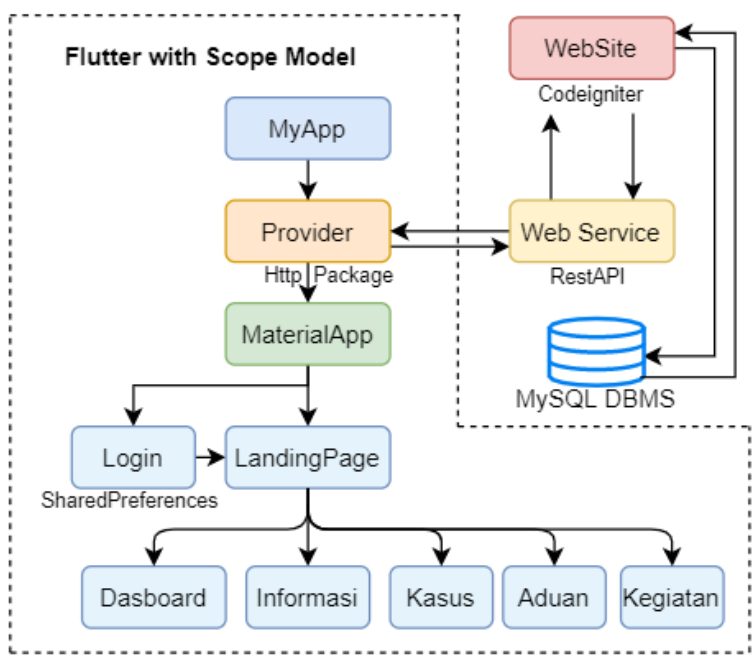

Gambar 8. Scope Model
Aplikasi secara default memanggil widget login sebagai home. Shared Preferences digunakan untuk mengenali apakah pengguna telah login atau belum, jika shared preferences bernilai true maka widget landing page yang dipanggil. Dalam landing page disediakan beberapa quick access menggunakan tabbar view seperti informasi, kasus, aduan, dan kegiatan. Pengguna dapat memilih halaman tersebut sesuai keperluan. Dalam setiap halaman telah ditampilkan data yang diperoleh dari web service. Update data disediakan dalam setiap halaman melalui widget form. Pertukaran data dengan web service dilakukan melalui http package menggunakan sebuah provider yang dipanggil oleh masing-masing widget sebagai consumer. Selanjutnya data yang telah diperoleh dalam bentuk json di decode terlebih dahulu untuk ditampilkan pada masing-masing widget.

Proses pendaftaran user dilakukan guna memperoleh data pengguna, khususnya untuk memastikan hanya pihakpihak yang yang diberikan akses yang dapat menggunakan aplikasi melalui fitur login. Gambar 9 merupakan tampilan form login dan pendaftaran. Proses pendaftaran memerlukan validasi oleh admin, beberapa 
fitur dalam aplikasi belum bisa digunakan seperti aduan, pendaftaran kegiatan, dan pendaftaran penerima BST hingga user divalidasi oleh admin.

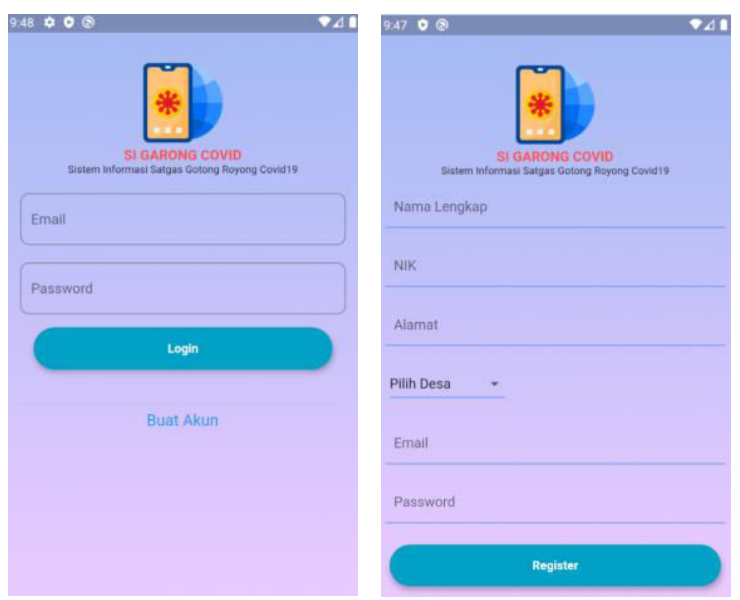

Gambar 9. Form Login dan Pendaftaran

Pengguna yang telah memiliki hak akses dapat melakukan login sesuai level user. Tampilan halaman pengguna yang telah divalidasi admin terlihat seperti pada gambar 10. Terdapat perbedaan akses menu antara level admin dan pengguna. Admin mendapat akses lebih untuk melakukan manajemen data kasus, aduan, kegiatan, informasi, penerima BST, dan manajemen pengguna.

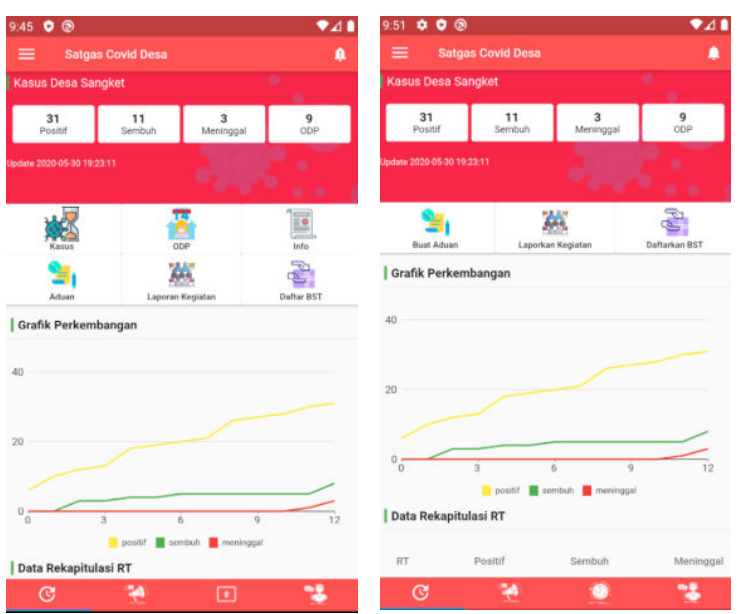

Gambar 10. Beranda Admin dan Pengguna

Manajemen data kasus merupakan fitur utama dalam aplikasi. Terdapat beberapa tipe kasus yaitu Orang Dalam Pengawasan (ODP), Pasien Dalam Pengawasan (PDP), Kasus Positif, Sembuh, dan Meninggal. Penambahan kasus baru dicatat secara detail baik identitas, alamat, tanggal konfirmasi, maupun keterangan lainnya yang dapat membantu petugas dalam pemantauan dan pengelolan kasus pada tingkat Desa, serta pengambilan keputusan terkait penanganan dampak pasca bencana. Tampilan manajemen kasus dapat dilihat pada gambar 11.

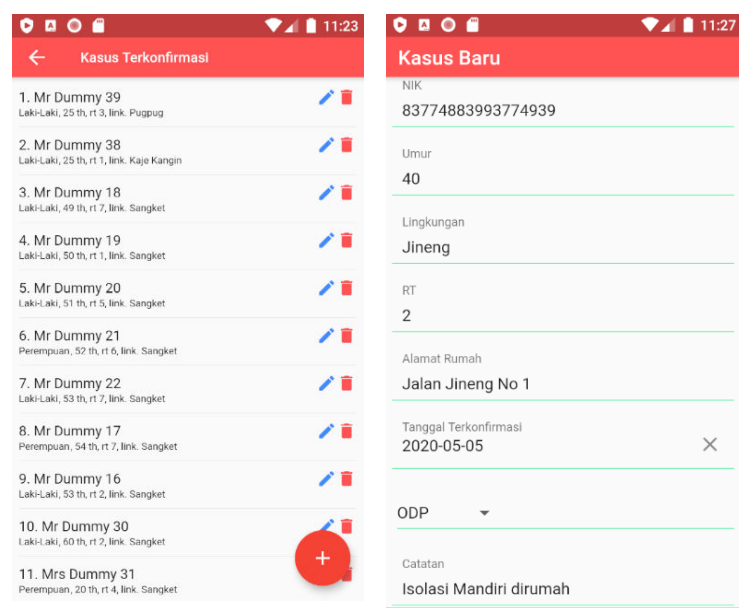

Gambar 11. Daftar Kasus dan Form Input Kasus

Manfaat lain juga dapat diperoleh dengan menampilkan data perkembangan kasus perhari dan rekapitulasi per RT, sehingga menjadi sebuah peringatan dini bagi masyarakat akan keberadaan kasus yang sudah masuk kedalam wilayah RT lingkungan tempat tinggal. Sebagai data pembanding, aplikasi juga menyediakan halaman yang menampilkan realtime update kasus setiap provinsi di Indonesia yang diperoleh dari open api service kawalcorona[18]. Selain sebagai pengingat bahaya pandemi ini, aplikasi dapat menjadi salah satu sarana memberikan edukasi dan informasi terkait kegiatan pencegahan Covid 19 yang dapat dilakukan masyarakat melalui halaman informasi terkini yang rutin diupdate oleh satgas. Tampilan mengenai perkembangan kasus, rekapitulasi kasus, dan informasi terkini dapat dilihat pada gambar 12. 


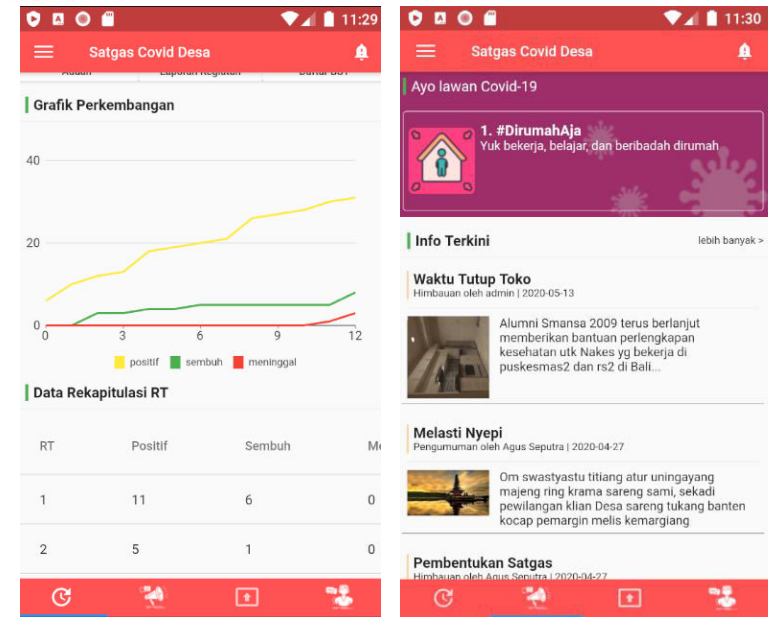

Gambar 12. Rekapitulasi Kasus dan Informasi Kegiatan

Penanganan Covid 19 tentu tidak bisa hanya dilakukan oleh Satgas, melainkan yang terpenting adalah kesadaran dan peran serta masyarakat. Oleh karena itu kritik, saran, maupun laporan masyarakat sangat dibutuhkan guna membantu Satgas dalam pemantauan dan pencegahan Covid 19. Komunikasi dua arah berusaha dilakukan oleh satgas dengan merespon aduan masyarakat terkait penanganan Covid 19 melalui halaman manajemen data aduan. Data aduan yang diperoleh menjadi salah satu laporan kinerja Satgas yang rutin dilakukan dalam satu minggu sekali, serta dapat dijadikan acuan dalam penentuan kebijakan terkait pelaksanaan kegiatan satu minggu berikutnya. Tampilan manajemen data aduan dan respon aduan oleh admin dapat dilihat pada gambar 13 .
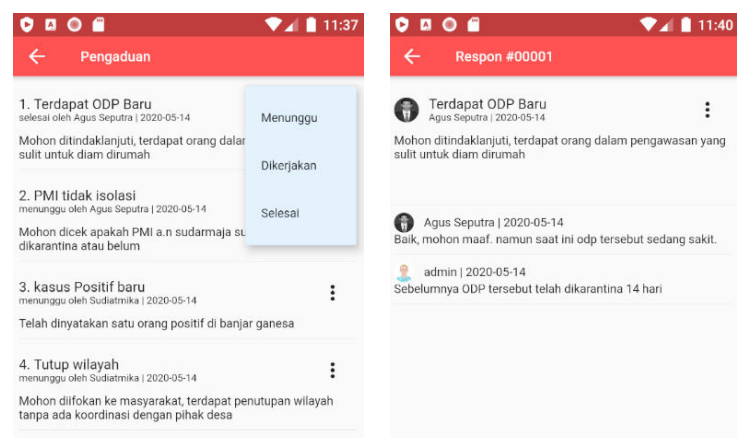

Gambar 13. Daftar Aduan dan Form Respon Aduan
Pembatasan kegiatan masyarakat juga menjadi tugas penting Satgas. Oleh karena itu pendataan kegiatan masyarakat yang melibatkan banyak orang menjadi salah satu langkah preventif yang dapat dilakukan. Masyarakat wajib melaporkan detail kegiatan yang akan dilaksanakan mulai dari jenis kegiatan, tujuan, penanggung jawab, lokasi, tanggal dimulai dan tanggal selesai kepada satgas melalui menu laporan kegiatan. Laporan kegiatan yang masuk harus divalidasi oleh admin, untuk kemudian dapat dilaksanakan oleh masyarakat.

Pengelolaan data penerima BST menjadi salah satu tugas Satgas yang sangat sensitif. Oleh karena itu, manajemen data BST harus dilakukan secara akuntabel. Mulai dari pendaftaran, penentuan penerima, hingga pembagian BST harus dilakukan secara hati-hati. Sebagai salah satu upaya menghadirkan keadilan kepada seluruh masyarakat, aplikasi juga dilengkapi fitur pendaftaran mandiri sebagai penerima BST oleh masyarakat. Pengguna dapat melakukan pendaftaran lebih dari satu kali untuk data yang berbeda, serta wajib mengisi data terkait pendaftaran penerima BST seperti nama kepala keluarga, NIK Kepala Keluarga, Nomor KK, dan bukti scan foto Kartu Keluarga pada form pendaftaran untuk selanjutnya divalidasi oleh Satgas. Sistem telah membatasi satu Kepala Keluarga dapat menerima satu BST dalam satu periode berdasarkan NO KK yang digunakan, diimbangi oleh validasi Satgas dapat menghindari kesalahan dalam penentuan penerima BST.

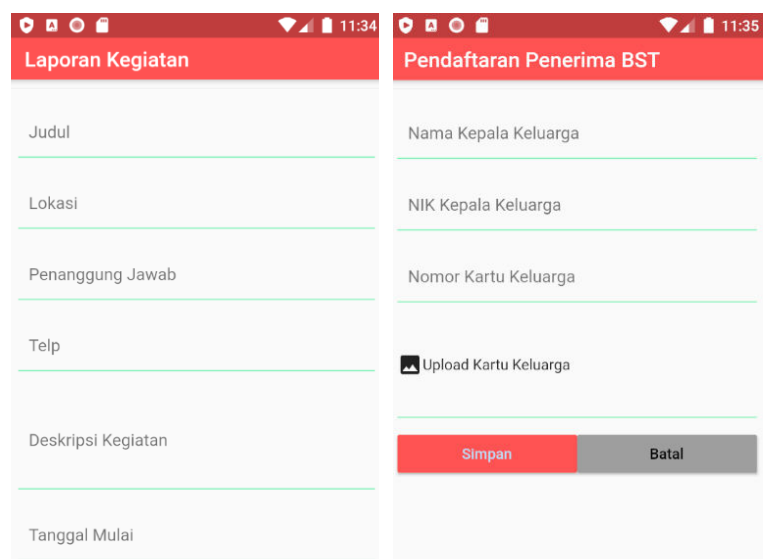


Gambar 14. Form Laporan Kegiatan dan Pendaftaran Penerima BST

\section{Implementasi}

Protitipe yang telah selesai dikembangkan wajib melalui serangkaian pengujian. Pengujian level sedang dilakukan menggunakan android emulator Nexus S API 26 dengan metode white box testing. Pengembangan aplikasi dalam bentuk modul memudahkan pengujian yang dilakukan, terutama berkaitan dengan perilaku aplikasi, user interface, interaksi antar modul, serta integrasi data melalui API [19].

Pengujian end-to-end penting dilakukan untuk mengetahui pengalaman pengguna yang mencakup beberapa modul penting dalam aplikasi. Pengujian pada tahap ini dilakukan langsung pada smartphone android 8.1 menggunakan Black box testing dengan beberapa kasus untuk mengetahui kesesuaian aplikasi yang dibangun dengan kebutuhan pengguna.

\section{Evaluasi}

Berdasarkan pengujian yang telah dilakukan pada tahap implementasi, diperoleh hasil sebagai berikut.

a. Pengujian white box memberikan hasil bahwa semua modul pada aplikasi dapat bekerja dengan baik berdasarkan rancangan sistem.

b. Pengujian black box memberikan kesimpulan bahwa aplikasi berhasil pada semua uji angket dan sesuai dengan kebutuhan pengguna.

\section{SIMPULAN}

Sistem Informasi Satgas Gotong Royong (SI GARONG) Covid 19 telah melalui tahap pengembangan sistem menggunakan metode ADDIE. Berdasarkan analisis, perancangan, pengembangan, implementasi, dan pengujian diperoleh kesimpulan sebagai berikut.

a. Pengembangan Si GARONG Covid 19 berbasis Mobile telah berhasil dilakukan sesuai dengan rancangan kebutuhan sistem, use case diagram, activity diagram, relationalship diagram, dan rancangan antarmuka.

b. Pengembangan dilakukan dengan menggunakan framework flutter untuk aplikasi mobile, dan framework codeigniter untuk pegembangan aplikasi website yang digunakan oleh administrator.

c. Hasil pengujian terhadap SI GARONG Covid 19 Mobile bahwa semua fungsi dalam aplikasi dapat berjalan dengan baik sesuai dengan kebutuhan pengguna.

d. Pengujian black box juga memberikan hasil bahwa pengguna merasa terbantu dalam kegiatan pemantauan aktivitas masyarakat, terutama berkaitan dengan pendataan kasus baru dan pelaporan kegiatan masyarakat.

Pada pengembangan selanjutnya seluruh data dalam aplikasi dapat digunakan untuk kepentingan laporan maupun pemulihan pasca pandemi. Pembuatan sistem seleksi penerima bantuan, hingga sistem pendataan penduduk terdampak dapat direncanakan menggunakan data yang diperoleh oleh aplikasi.

\section{REFERENSI}

[1] A. Pribadiono, "Lembaga Desa Adat dalam Pembangunan Desa Menurut UU No. 6 Tahun 2014: antara Kemandirian dan Subordinasi Pengaturan," Lex Jurnalica, vol. 13, no. 1 April, 2016.

[2] Suyatra, "Dua Dadia di Sudaji Ngaben Massal, Perbekel dan Bendesa Dipanggil," Bali Express, 2020.

[3] M. D. A. P. B. Pemerintah Provinsi Bali, Keputusan bersama Gubernur Bali dan Majelis Desa Adat Provinsi Bali No. 472/1571/PPDA/DPMA dan No. 05/SKMMA-Prov Bali/III/2020 tentang pembentukan Satuan Tugas Gotong Royong Percepatan Covid19 berbasis Desa Adat di Bali. 2020.

[4] K. Shah, H. Sinha, and P. Mishra, "Analysis of Cross-Platform Mobile App Development Tools," 2019 IEEE 5th Int. Conf. Converg. Technol. I2CT 2019, pp. 1-7, 2019.

[5] A. Belkhir, M. Abdellatif, R. Tighilt, N. Moha, Y. G. Gueheneuc, and E. Beaudry, "An observational study on the state of REST API uses in 
android mobile applications," Proc. 2019 IEEE/ACM 6th Int. Conf. Mob. Softw. Eng. Syst. MOBILESoft 2019, pp. 66-75, 2019.

[6] D. Rathod, "Performance Evaluation of Restful Web Services and Soap / Wsdl Web Services," Int. J. Adv. Res. Comput. Sci., vol. 8, no. 7, pp. 415420, 2017.

[7] A. Agocs, "A web service based on RESTful API and JSON

Schema/JSON Meta Schema to construct knowledge graphs," 2018 Int. Conf. Comput. Inf. Telecommun. Syst., pp. 1-5, 2018.

[8] "Latest Specification (v1.0)," www.jsonapi.org. [Online]. Available: https://jsonapi.org/format. [Accessed: 23-Sep-2020].

[9] R. Gunawan and A. Rahmatulloh, "JSON Web Token (JWT) untuk Authentication pada Interoperabilitas Arsitektur berbasis RESTful Web Service," J. Edukasi dan Penelit. Inform., vol. 5, no. 1, p. 74, 2019.

[10] A. Rahmatulloh, R. Gunawan, and F. M. S. Nursuwars, "Performance comparison of signed algorithms on JSON Web Token," IOP Conf. Ser. Mater. Sci. Eng., vol. 550, no. 1, 2019.

[11] S. Simon and A. Hampus, "CrostPlatform Framework Comparison Flutter \& React Native," Blekinge Institute of Technology, Sweden, 2020.

[12] W. Wu, "React Native vs Flutter, cross-platform mobile application frameworks," Metrop. Univ., no. March, p. 28, 2018.

[13] L. Gu, J. Wang, and L. Ma,
"Research and Development for Android Platform," Int. J. Multimed. Ubiquitous Eng., vol. 9, no. 4, pp. 187-198, 2014.

[14] R. Woods, "ADDIE vs. SDLC: A Comparison," in World Conference on E-Learning in Corporate, Government, Healthcare, and Higher Education, 2019, pp. 427-442.

[15] I. M. H. Antara, I. G. M. Darmawiguna, and I. M. A. Pradnyana, "Pengembangan Aplikasi Mobile Crowdsourcing Informasi Layanan Umum (Studi Kasus di Kabupaten Buleleng)," Kumpul. Artik. Mhs. Pendidik. Tek. Inform., vol. 8, no. 2, p. 154, 2019.

[16] M. Larassati, A. Latukolan, A. Arwan, and M. T. Ananta, "Pengembangan Sistem Pemetaan Otomatis Entity Relationship Diagram Ke Dalam Database," J. Pengemb. Teknol. Inf. dan IImu Komput., vol. 3, no. 4, pp. 4058-4065, 2019.

[17] A. Bizzotto, "Flutter: Global Access vs Scoped Access with Provider," Medium, 2019. [Online]. Available: https://medium.com/coding-withflutter/flutter-global-access-vsscoped-access-with-provider8d6b94393bdf.

[18] Ethical Hacker Indonesia, "Kawal Corona API," 2019. [Online]. Available: https://kawalcorona.com/api/.

[19] Google Developers, "Fundamentals of Testing," Google Developers. [Online]. Available: https://developer.android.com/trainin g/testing/fundamentals. 